\title{
The effects of a 6-month Schroth intervention for Adolescent Idiopathic Scoliosis (AIS): preliminary analysis of an ongoing randomized controlled trial
}

\author{
Sanja Schreiber ${ }^{*}$, Eric C Parent, Douglas M Hedden, Marc Moreau, Douglas Hill, Elise M Watkins \\ From 10th International Conference on Conservative Management of Spinal Deformities - SOSORT 2013 \\ Annual Meeting \\ Chicago, IL, USA. 8-11 May 2013
}

\section{Background}

Literature lacks strong evidence on the effect of exercises on scoliosis[1]. Schroth scoliosis-specific exercises have shown promising results in studies of suboptimal quality.

\section{Purpose}

The purpose of this study was to evaluate the effect of Schroth exercises on back endurance in patients with AIS using the Scoliosis Research Society-22r (SRS-22r) and Self-Efficacy (SEQ) questionnaires.

\section{Methods}

A total of 31 patients with AIS, aged 10-18, with curves from $10^{\circ}-45^{\circ}$, wearing a brace or not, participated. Sixteen were randomized to Schroth with standard care, and 15 to standard care alone (monitoring or bracing) for six months. The Schroth intervention consisted of five individual visits to learn the exercises, followed by weekly supervised group sessions of one hour each, with daily home exercises prescribed using an algorithm [2] (45 minutes per day). Compliance was monitored with a logbook, and outcomes were recorded at baseline and six months. Effect sizes were estimated using Cohen's d, which corresponds to the mean difference between the groups in the change observed from baseline to six months (Schroth - standard care), divided by the pooled standard deviation at baseline (Cohen's $\mathrm{d} \geq 0.8=$ large, $0.5-0.8=$ moderate, $0.2-0.5=\operatorname{small}[3]$ ).

\section{Results}

Two controls and one Schroth group participant dropped out. Mean age was $14.4 \pm 2.1 \mathrm{yrs}$ for Schroth and 13.7 \pm 1.7 yrs for controls; mean Cobb angles were $32.6 \pm 7.9 \mathrm{o}$ and $28.8 \pm 10.0$ o, respectively. Schroth participants with complete follow-up attended $87 \pm 8 \%$ of the prescribed weekly exercise sessions and completed $86 \pm 5 \%$ of the prescribed home exercises. Intention-to-treat analysis lowered compliance to $83 \pm 19 \%$ and $81 \pm 17 \%$ for weekly sessions and home program, respectively. Effect sizes at six months for the SRS-22r were smaller than expected, but favored the Schroth group with Cohen's d: pain $=0.09$, selfimage $=0.09$, function $=0.00$ and total $=0.21$. The effect sizes for self-efficacy (0.18) and for the Biering-Sorensen test (0.28) also favored Schroth. The perceived mean global rating of change in the Schroth group was 3.8 \pm 2.2 , corresponding to moderate improvement, and $-0.3 \pm 1.7$ in the standard care group, corresponding to a small amount of deterioration.

\section{Conclusions and discussion}

The dropout rate was low (9.7\%), which was reflective of the patients' commitment to the therapy. Outcomes favored the Schroth group. In this preliminary analysis, Schroth exercises showed a small but positive influence on self-efficacy, self-image, pain and back muscle endurance.

* Correspondence: sbosnjak@ualberta.ca

University of Alberta, Faculty of Rehabilitation Medicine, Alberta, Canada 


\section{References}

1. Fusco C, Zaina F, Atanasio S, Romano M, Negrini A, Negrini S: Physical exercises in the treatment of adolescent idiopathic scoliosis: an updated systematic review. Physiother Theory Pract 2011, 27(1):80-114.

2. Watkins EM, Bosnjak S, Parent EC: Algorithms to prescribe Schroth exercises for each of four Schroth curve types. Scoliosis 2012, 7(Suppl 1):P22.

3. Cohen J: Statistical Power Analysis for the Behavioral Sciences. Routledge Academic 21988

doi:10.1186/1748-7161-8-S2-O44

Cite this article as: Schreiber et al:: The effects of a 6-month Schroth

intervention for Adolescent Idiopathic Scoliosis (AIS): preliminary

analysis of an ongoing randomized controlled trial. Scoliosis 2013

8(Suppl 2):O44.

\section{Submit your next manuscript to BioMed Central} and take full advantage of:

- Convenient online submission

- Thorough peer review

- No space constraints or color figure charges

- Immediate publication on acceptance

- Inclusion in PubMed, CAS, Scopus and Google Scholar

- Research which is freely available for redistribution

Submit your manuscript at www.biomedcentral.com/submit 